\title{
Retrospective analysis of patients with relapsed/refractory medulloblastoma after autologous stem cell transplantation
}

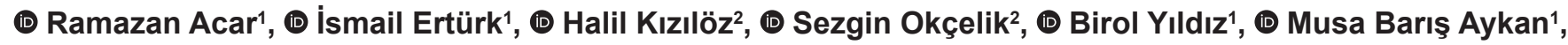 \\ (1) Gül Sema Yıldıran Keskin¹, (1) Erdim Sertoğlu³, (1) Bilgin Bahadır Başgöz ${ }^{4}$, (1) Nuri Karadurmuş ${ }^{1}$ \\ 1 University of Health Sciences Turkey, Gülhane Training and Research Hospital, Clinic of Medical Oncology, Ankara, Turkey \\ 2Nevsehir State Hospital, Clinic of Urology, Nevsehir, Turkey \\ 3 University of Health Sciences Turkey, Gülhane Training and Research Hospital, Clinic of Biochemistry, Ankara, Turkey \\ 4University of Health Sciences Turkey, Gülhane Training and Research Hospital, Clinic of Internal Medicine, Ankara, Turkey
}

\section{Date submitted: \\ 01.06.2020}

Date accepted:

10.08.2020

Online publication date:

15.12.2020

\section{Corresponding Author:}

Ramazan Acar MD, University of Health Sciences Turkey, Gülhane Training and Research Hospital, Clinic of Medical Oncology, Ankara, Turkey dr_racar@yahoo.com

ORCID:

orcid.org/0000-0002-3094-899X

Keywords: Ifosfamide, carboplatin, etoposide, autologous hematopoietic stem cell transplantation, adult medulloblastoma

\begin{abstract}
Aims: Medulloblastoma is very rare and accounts for only $1 \%$ of intracranial tumors in adults. There are limited treatment options for adult medulloblastoma patients who have relapsed or refractory disease. We aimed to show real-life data on health outcomes in adult patients with recurrent or refractory medulloblastoma patients who received autologous hematopoietic stem cell transplantation (AHSCT).
\end{abstract}

Methods: We analyzed the data of 15 patients who underwent AHSCT after ifosfamide, carboplatin, and etoposide (ICE) as high-dose chemotherapy (HDCT) regimen for relapsed or refractory medulloblastoma from 2010 to 2020. Overall response rate (ORR), overall survival (OS) and progression-free survival (PFS) of the patients were evaluated.

Results: Fifteen patients were observed in this study. The mean age of the study group was $27.9 \pm 8.1$ years and $53.3 \%$ of the patients were female $(n=8)$. ORR was $100 \%$. The median OS and PFS were 24 months [95\% confidence interval $(\mathrm{Cl}): 11.4-36.5$ ] and 13 months (95\% Cl: 10.215.8), respectively. One-year OS and PFS rates were $77 \%$ and $55.2 \%$, respectively. Five-year OS rate was $82.5 \%$.

Conclusions: AHSCT with ICE as HDCT regimen is a safe and effective treatment option for relapsed or refractory adult medulloblastoma patients with an acceptable ORR, OS and PFS time.

\section{Introduction}

Medulloblastoma is the most common central nervous system embryonal tumor of childhood, constituting $25 \%$ of all intracranial neoplasms (1). In contrast, adult medulloblastoma is very rare and accounts for only $1 \%$ of intracranial tumors (2). Current conventional management of adult medulloblastoma involves maximum safe resection followed by craniospinal radiation with or without concurrent adjuvant chemotherapy depending on the clinical risk classification (3). Clinical risk stratification included age, the extent of resection, metastatic status, and tumor biology (4). Metastatic patients might undergo chemotherapy. Besides, autologous hematopoietic stem cell transplantation (AHSCT) should be selected (5). In the literature, a limited number of patients underwent high-dose chemotherapy (HDCT) and AHSCT due to relapsed or refractory medulloblastoma even after surgical debulking and radiotherapy $(6,7)$. According to the literature, data about AHSCT in adult medulloblastoma patients appear to be small case series. Similar treatment methods are used in Turkey. The only center which use AHSCT in solid organ tumor in Turkey is the Gülhane Training and Research Hospital Medical Oncology Department. The other oncology departments in Turkey are sending their 
medulloblastoma patients to our center for treating with AHSCT. Therefore, the results reflect the data of Turkey.

We aimed to demonstrate the real-life data about relapsed or refractory medulloblastoma patients who received HDCT and AHSCT and to increase the awareness of this rare treatment choice.

\section{Methods}

\section{Study Design and Patients}

The study was carried out by investigating the patients with relapsed and refractory adult medulloblastoma, who had received HDCT and AHSCT in University of Health Sciences Turkey, Gülhane Training and Research Hospital between January 2010 and March 2020 in diagnosis, follow-up, treatment, complications outcomes. The study is a single-center, retrospective study.

A retrospective case control study was carried out with 15 cases that were previously diagnosed and treated or currently on a treatment for medulloblastoma, and they were evaluated in terms of demographic characteristics, cancer specific features including histology, stage of the cancer, previous or ongoing treatment and previous surgery or radiotherapy.

The patients received ifosfamide at a total dose of $12 \mathrm{gr} / \mathrm{m}^{2}$ divided six days on days -8 to -3 , carboplatin at a total dosage of $1,200 \mathrm{mg} / \mathrm{m}^{2}$ divided six days on days -8 to -3 and etoposide at a total dosage $1,200 \mathrm{mg} / \mathrm{m}^{2}$ divided six days on days -8 to -3 ifosfamide, carboplatin, and etoposide (ICE) as HDCT (8). After chemotherapy, the patients rested on days -2 and -1 . Autologous stem cells were reinfused on day 0 . We infused at least 3 million $\left(3 \times 10^{6}\right)$ CD34+ stem cells. After infusions, all patients were followed in our Stem Cell Infusion Center. All patient rooms were single, isolated with a special ventilation system. During the stem cell transplant process, patients' relatives were forbidden to visit and bring food from outside for protecting them from infections.

The primary endpoint of this study was to assess the progression-free survival (PFS) and overall survival (OS) periods. Secondary endpoints were to identify prognostic clinical factors for disease progression after AHSCT, and to define the safety and the toxicity profile of the HDCT and AHSCT.

The ethics committee of University of Health Sciences Turkey, Gülhane Training and Research Hospital approved the study with 2020-112 ethical committee number on March 10, 2020. All procedures were performed in accordance with the Helsinki Declaration of 1975 , which was revised in 2008 , and all procedures were convenient to the ethical standards of the responsible committee on human experimentation (institutional and national).

\section{Data Collection}

Medical records of the patients, who were admitted to the Department of Medical Oncology at the University of Health
Sciences Turkey, Gülhane Training and Research Hospital and eventually diagnosed with medulloblastoma, were investigated whether they previously or currently had received AHSCT. Medical records of suitable cases were enrolled in a SPSS datasheet by the registered staff of Department of Oncology at the University of Health Sciences Turkey.

\section{Statistical Analysis}

Patients' demographics, clinical and biochemical features, and clinical and radiologic outcomes were recorded on an SPSS v.17 (SPSS Inc., Chicago, IL USA) data sheet considering the patients' confidentiality. Data were accessible only by the authorized institutional staff and caregivers. The Student's t-test was utilized for evaluating normal distribution of data. Demographic indices provided the mean values with the standard deviation or the median values as appropriate. Frequencies were noted in numbers with percentiles. Survival analysis was conducted utilizing the KaplanMeier tables and survival plots provided.

\section{Results}

\section{Patient and Disease Characteristics}

We determined that 50 patients were followed up with the diagnosis of medulloblastoma between January 2010 and March 2020. Fifteen of the patients $(30 \%)$ received HDCT and AHSCT. The mean age of the study group was $27.9 \pm 8.1$ years and $53.3 \%$ of the patients were female $(n=8)$. All patients were stage 4 at the time of diagnosis. Tumor histology revealed classic type medulloblastoma in 12 (80\%) patients and three (20\%) patients showed desmoplastic/nodular type medulloblastoma at diagnosis. Large anaplastic type and extensive nodular types were not observed. Bone was the most seen metastatic site [4 (26.7\%)] among the patients included in the study. Lymphoid nodes and lungs were the other most common metastatic sites, respectively. Three patients $(20 \%)$ of them had more than two metastatic sites. Numbers of lines before AHSCT treatment were more than three in all cases. Six $(40 \%)$ of the patients were treated with AHSCT as the third line therapy. Nine (60\%) of them were treated with AHSCT as the fourth line therapy (Table 1). Eleven patients had complete response $(73.3 \%)$, two patients had partial response $(13.3 \%)$ and two patients had stabile disease (13.3\%). Progression was not observed at the first controls. Overall response rate (ORR) was $100 \%$. Later in long term follow-up period, we detected progression. All cases received radiotherapy as the first line therapy after surgery. They underwent different combination therapies for the second, third and fourth lines (Table 1).

\section{Treatment Administration and Survival Outcome}

All cases underwent AHSCT following various degrees of salvage chemotherapy both before and after surgery due to relapsed or refractory disease. As HDCT, all patients received ICE regimen. The mean and median follow-up times 
following AHSCT were 15.1 \pm 18.4 months and seven months, respectively. The median OS and PFS were as follows; 24 months [95\% confidence interval $(\mathrm{Cl}): 11.4-36.5]$ and 13 months (95\% Cl: 10.2-15.8), respectively (Figure 1, 2, Table 2). OS and PFS at the $12^{\text {th }}$ month were $77 \%$ and $55.2 \%$, respectively. Fiveyear OS was $82.5 \%$.

\section{Toxicity of AHSCT}

The numbers of side effects related to AHSCT are demonstrated in Table 3. Leukopenia, anemia, thrombocytopenia, neurotoxicity, febrile neutropenia, diarrhea and vomiting/nausea were found $100 \%, 100 \%, 100 \%$, $46.6 \%, 100 \%, 66.6 \%$, and $100 \%$, respectively. Majority of the patients received erythrocyte, thrombocyte transfusions and granulocyte colony stimulating factors several times after 12 or 16 days following the AHSCT. Eleven patients $(73.3 \%$ ) had grade 4 thrombocytopenia. No bleeding was observed in any patients. Grade 2 and 3 febrile neutropenia were observed among all patients. A broad-spectrum antibacterial therapy was administered in all patients, including $3^{\text {rd }}$ generation

Table 1. The demographic and disease-related characteristics of the patients

\begin{tabular}{|c|c|c|c|c|}
\hline Features & & n (\%) & Mean \pm SD & Median \\
\hline Age (years) & & $15(100)$ & $27.9 \pm 8.1$ & $27(18-43)$ \\
\hline \multicolumn{5}{|l|}{ Gender } \\
\hline Male & & $7(46.7)$ & & \\
\hline Female & & $8(53.3)$ & & \\
\hline \multicolumn{5}{|l|}{ Histopathology } \\
\hline Classic type & & $12(80)$ & & \\
\hline Desmoplastic/nodular type & & $3(20)$ & & \\
\hline Large/anaplastic type & & $0(0)$ & & \\
\hline Extensive nodular type & & $0(0)$ & & \\
\hline \multicolumn{5}{|l|}{ Stage at the time of diagnosis } \\
\hline 4 & & $15(100)$ & & \\
\hline \multicolumn{5}{|l|}{ Site of metastases } \\
\hline No metastases & & $0(0)$ & & \\
\hline Liver & & $2(13.3)$ & & \\
\hline Lymph node & & $3(20)$ & & \\
\hline Lung & & $3(20)$ & & \\
\hline Bone & & $4(26.7)$ & & \\
\hline More than 1 sites & & $3(20)$ & & \\
\hline \multicolumn{5}{|l|}{ The response of the patients after AHSCT } \\
\hline Stable response & & $2(13.3)$ & & \\
\hline Partial response & & $2(13.3)$ & & \\
\hline Complete response & & $11(73.4)$ & & \\
\hline Progressive disease & & $0(0)$ & & \\
\hline \multicolumn{5}{|c|}{ The treatments lines patients received before AHSCT } \\
\hline Treatments & $\begin{array}{l}\text { First line: } \\
\text { n (\%) }\end{array}$ & $\begin{array}{l}\text { Second line: } \\
\text { n (\%) }\end{array}$ & $\begin{array}{l}\text { Third line: } \\
\text { n (\%) }\end{array}$ & $\begin{array}{l}\text { Fourth } \\
\text { line: } \\
\text { n (\%) }\end{array}$ \\
\hline Radiotherapy & $15(100)$ & $1(6.7)$ & & \\
\hline Vincristine+Procarbazine+Mustard & & $3(20)$ & & \\
\hline Cisplatin+Etoposide+Cyclophosphamide & & $8(53.3)$ & $1(6.7)$ & \\
\hline Cisplatin+Lomustine+Vincristine & & $1(6.7)$ & & \\
\hline Ifosfamide+Carboplatin+Etoposide & & $2(13.3)$ & $5(33.3)$ & \\
\hline HDCT (ICE) + AHSCT & & & $6(40)$ & $9(60)$ \\
\hline
\end{tabular}


cephalosporins, teicoplanin, anti-pseudomonal azlo-ureido penicillin, carbapenems, linezolid and macrolides for empirical purpose. Blood and urine cultures were taken. No bacteria or fungal infections were seen. There was no life-threatening

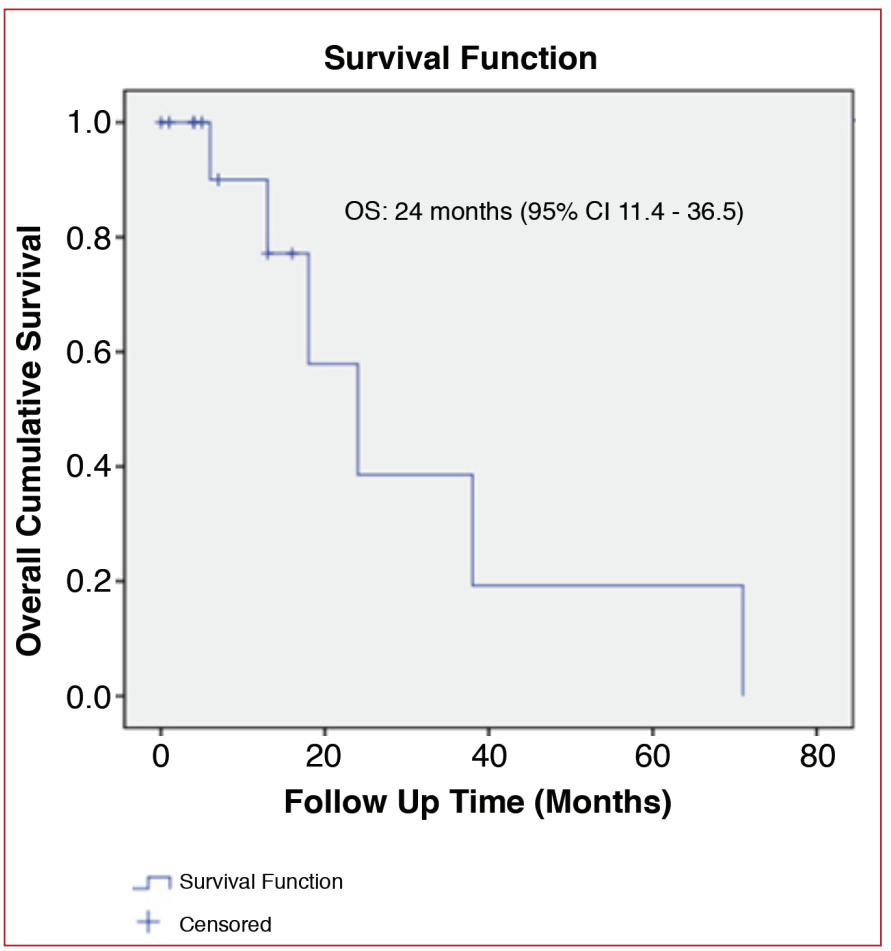

Figure 1. Overall survival of patients underwent autologous hematopoietic stem cell transplantation treatment (Kaplan-Meier curve) OS: Overall survival, Cl: Confidence interval

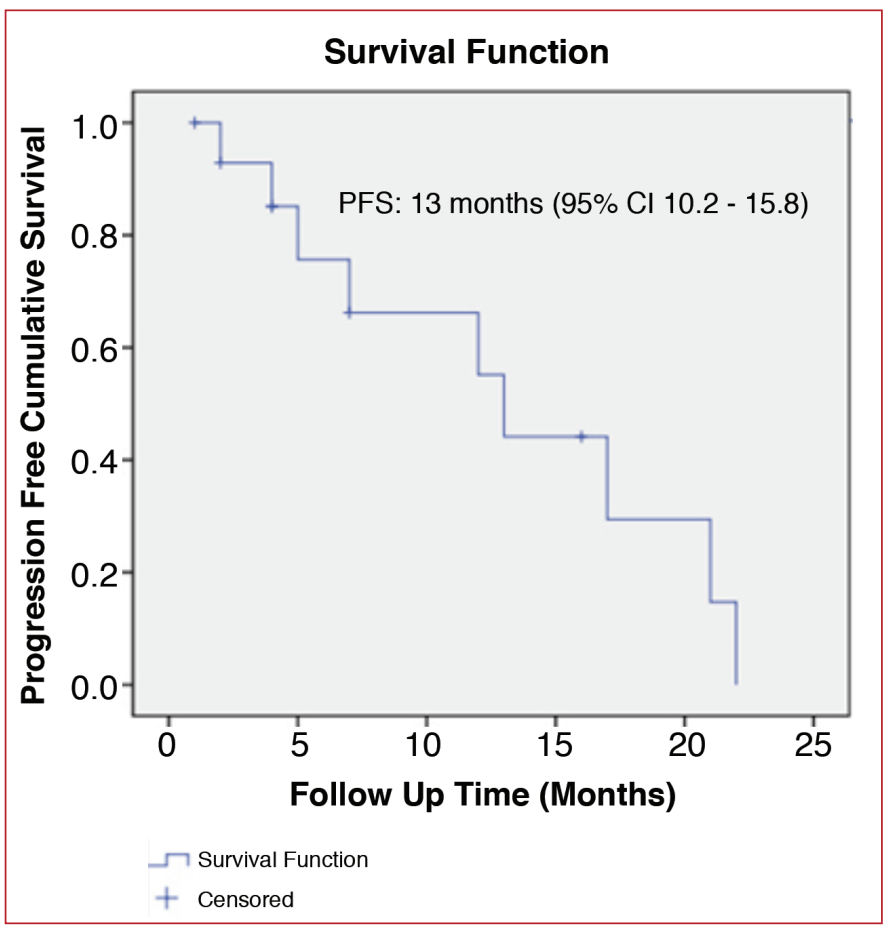

Figure 2. Progression free survival of patients underwent autologous hematopoietic stem cell transplantation treatment (Kaplan-Meier curve) PFS: Progression-free survival, Cl: Confidence interval toxicity. One patient had reversible grade 3 renal toxicity. No death was observed relating to the treatment. There was no death in the first 100 days. Six (40\%) patients died due to the disease progression at the follow-up period.

\section{Discussion}

Medulloblastoma treatment is based on clinical risk stratification (3). Current therapy combines surgery, chemotherapy, radiotherapy, and HDCT with AHSCT (9). In this study, we analyzed the efficacy and safety of HDCT with ICE regimen and AHSCT treatment in patients with relapsed or refractory adult medulloblastoma, who underwent at least three lines of therapy before. All patients underwent surgery. Before AHSCT, all patients had radiotherapy as the first-line therapy. As a second-line therapy, they received combination chemotherapies such as Vincristine plus Procarbazine plus Mustard, Cisplatin plus Etoposide plus Cyclophosphamide, Cisplatin plus Lomustine plus Vincristine or Ifosfamide plus Carboplatin plus Etoposide $(10,11)$. Medulloblastoma is a high risk for most of our patients that received AHSCT as the third-line therapy. According to the packer staging criteria, which included age, the extent of resection, metastatic status, and tumor biology, all patients in our study were high-risk and additionally as far as we know, medulloblastomas are chemosensitive tumors $(12,13)$. There were several retrospective studies about AHSCT in medulloblastoma $(6,7)$. Most of them consisted of pediatric patients. Various HDCT regimens were applied before AHSCT. Moreover, all patients were stage four at diagnosis. All the patients received ICE regimen as HDCT in our study.

Histologically, medulloblastoma is an embryonal neuroepithelial tumor originating from the cerebellum and dorsal brain stem. Classic, desmoplastic/nodular, large cell/anaplastic, and extensive nodularity are the subgroups of medulloblastoma. The most common histologic variant is classic medulloblastoma in both children and adults $(70-80 \%)$, and the least common is

Table 2. Overall survival and progression free survival of patients underwent autologous hematopoietic stem cell transplantation treatment

\begin{tabular}{|c|c|c|c|}
\hline & n (\%) & Median & Mean \pm SD \\
\hline OS & & $\begin{array}{l}24 \text { months } \\
(95 \% \mathrm{Cl}: 11.4-36.5)\end{array}$ & \\
\hline PFS & & $\begin{array}{l}13 \text { months } \\
(95 \% \mathrm{Cl}: 10.2-15.8)\end{array}$ & \\
\hline 12 months OS & 77 & & \\
\hline 12 months PFS & 55.2 & & \\
\hline 5 years OS & 82.5 & & \\
\hline $\begin{array}{l}\text { The duration of } \\
\text { follow-up time }\end{array}$ & & $7(3-71)$ & $15.1 \pm 18.4$ \\
\hline \multicolumn{4}{|c|}{$\begin{array}{l}\text { OS: Overall survival, PFS: Progression free survival, AHSCT: Autologous } \\
\text { hematopoietic stem cell transplantation, SD: Standard deviation, CI: Confidence } \\
\text { interval }\end{array}$} \\
\hline
\end{tabular}


medulloblastoma with extensive nodularity $(3 \%)(14,15)$. We observed classic type medulloblastoma in $12(80 \%)$ patients and desmoplastic/nodular type medulloblastoma in three $(20 \%)$ patients at diagnosis.

The five-year survival rate for both children and adult medulloblastoma is intermediate and about $70 \%$. SHH subtype predicts poor prognosis. SHH, WNT, and group 4 are detected

Table 3. Toxicities during autologous hematopoietic stem cell transplantation treatment

\begin{tabular}{|c|c|}
\hline & n (\%) \\
\hline \multicolumn{2}{|c|}{ Leukopenia } \\
\hline Grade 4 & $15(100)$ \\
\hline \multicolumn{2}{|l|}{ Anemia } \\
\hline No & $0(0)$ \\
\hline Grade 1 & $1(6.7)$ \\
\hline Grade 2 & $10(66.7)$ \\
\hline Grade 3 & $4(26.6)$ \\
\hline \multicolumn{2}{|c|}{ Thrombocytopenia } \\
\hline No & $0(0)$ \\
\hline Grade 1 & $0(0)$ \\
\hline Grade 2 & $1(6.7)$ \\
\hline Grade 3 & $3(20)$ \\
\hline Grade 4 & $11(73.3)$ \\
\hline \multicolumn{2}{|c|}{ Neurotoxicity } \\
\hline No & $8(53.3)$ \\
\hline Grade 1 & $3(20)$ \\
\hline Grade 2 & $4(26.7)$ \\
\hline \multicolumn{2}{|c|}{ Febrile neutropenia } \\
\hline No & $0(0)$ \\
\hline Grade 1 & $0(0)$ \\
\hline Grade 2 & $14(93.3)$ \\
\hline Grade 3 & $1(6.7)$ \\
\hline \multicolumn{2}{|c|}{ Vomiting/nausea } \\
\hline No & $0(0)$ \\
\hline Grade 1 & $1(6.7)$ \\
\hline Grade 2 & $2(13.3)$ \\
\hline Grade 3 & $9(60)$ \\
\hline Grade 4 & $3(20)$ \\
\hline \multicolumn{2}{|l|}{ Diarrhea } \\
\hline No & $5(33.3)$ \\
\hline Grade 1 & $2(13.3)$ \\
\hline Grade 2 & $7(46.7)$ \\
\hline Grade 3 & $1(6.7)$ \\
\hline \multicolumn{2}{|c|}{ The final status of the patients } \\
\hline Exitus & $6(40)$ \\
\hline Alive & $9(60)$ \\
\hline
\end{tabular}

$60 \%, 15 \%$, and $25 \%$ of adult patients, respectively (16). Fiveyear survival rate is $80 \%$ in adults who have WNT subtype. In our study SHH, WNT and group 4 were detected as $80 \%(n=12)$, $6.7 \%(n=1)$ and $13.3 \%(n=2)$, respectively and 5 -year survival was $82.5 \%$. This was similar to the literature.

Some studies showed ORRs in the range of $83-100 \%$ (5-7). Okada et al. (8) observed ORR in $83 \%$ patients who underwent ICE regimen as HDCT. Zia et al. (6) observed ORR in $100 \%$ of patients who underwent carboplatin, etoposide, and cyclophosphamide. Both of these studies had six children patients. We observed ORR as $100 \%$ in 15 patients. Later progression developed in eight patients. Six of them died in the follow-up $(40 \%, n=6)$. Nine patients are still alive. Six of the alive patients have complete remission. Three patients are still receiving treatment.

Zia et al. (6) showed an average of 13.5 months of PFS and an average of 21.5 months of OS after AHSCT. Additionally, Zia et al. (6) reported the median 26.8 months of OS for the medulloblastoma patients receiving AHSCT (6). In our study, we observed OS and PFS at the $12^{\text {th }}$ month as $77 \%$ and $55.2 \%$, respectively. The OS rate for five years was $82.5 \%$. These results were similar to previous literature.

Okada et al. (8) reported that the rate of grade 4 neutropenia and thrombocytopenia were observed to be $100 \%$. The toxicities were recovered within 26 days. Safety analysis of this report showed the feasibility of the ICE regimen as HDCT and AHSCT in patients with heavily pretreated medulloblastoma. In our study, all toxicities were observed.

Although this study had a small sample size of medulloblastoma patients with further line AHSCT and long follow-up, there are some limitations to report. It was a retrospective study, and the patient population was relatively heterogeneous. The patient sample size was small. Medulloblastoma patients in this study underwent AHSCT for metastatic medulloblastoma at an experienced highvolume referral center. We believe that these patients need multidisciplinary expertise and hence should be treated at centers of stem cell transplantation with excellence. The strengths of the study include AHSCT in further lines and relatively more patients in a rare disease. The results cannot be applied to other countries with different cancer epidemiology and practice.

\section{Conclusion}

In conclusion, AHSCT with ICE regimen remains one of the best determined systemic treatment options for progressive adult medulloblastoma patients. Also, the treatment was associated with good efficacy and tolerability.

\section{Acknowledgements}

We thank to Management of the Gülhane Training and Research Hospital and our patients and their families who participated in the research devotedly. 


\section{Ethics}

Ethics Committee Approval: The ethics committee of University of Health Sciences Turkey, Gülhane Training and Research Hospital approved the study with 2020-112 ethical committee number on March 10, 2020.

Informed Consent: Retrospective study.

Peer-review: Externally peer-reviewed.

\section{Authorship Contributions}

Concept: E.S., B.B.B., Design: E.S., B.B.B., Data Collection or Processing: R.A., İ.E., Analysis or Interpretation: B.Y., M.B.A., G.S.Y.K., Literature Search: E.S., N.K., H.K., S.O., Writing: E.S., B.B.B.

Conflict of Interest: No conflict of interest was declared by the authors.

Financial Disclosure: The authors declared that this study received no financial support.

\section{References}

1. Farwell JR, Dohrmann GJ, Flannery JT. Medulloblastoma in childhood: an epidemiological study. J Neurosurg. 1984;61:657-664.

2. Merchant TE, Pollack IF, Loeffler JS. Brain tumors across the age spectrum: biology, therapy, and late effects. Semin Radiat Oncol. 2010;20:58-66.

3. Bolek TW, McCollough WM, Maria BL,et al. Medulloblastoma: time-dose relationship based on a 30 year review. Int J Radiat Oncol Biol Phys. 1998;42:147154.

4. Gottardo NG, GajjarA. Current therapy for medulloblastoma. Curr Treat Options Neurol. 2006;8:319-334.

5. Majd N, Penas-Prado M. Updates on management of adult medulloblastoma. Curr Treat Options Oncol. 2019;20:64.

6. Zia M, Forsyth P, Chaudhry A, Russell J, Stewart D. Possible benefits of high-dose chemotherapy and autologous stem cell transplantation for adults with recurrent medulloblastoma. Bone Marrow Transplant. 2002;30:565-569.
7. Dunkel IJ, Gardner SL, Garvin JH, Goldman S, Shi W, Finlay JL. High-dose carboplatin, thiotepa, and etoposide with autologous stem cell rescue for patients with previously irradiated recurrent medulloblastoma. Neuro-oncology. 2010;12:297-303.

8. Okada S, Hongo T, Sakaguchi K, Suzuki K, Nishizawa S, Ohzeki T. Pilot study of ifosfamide/carboplatin/etoposide (ICE) for peripheral blood stem cell mobilization in patients with high-risk or relapsed medulloblastoma. Childs Nerv Syst. 2007;23:407-413.

9. Bouffet E. Management of high-risk medulloblastoma. Neurochirurgie. 2019;20;S0028-S3770:30178-X.

10. Brandes A, Franceschi E, Tosoni A, et al. Efficacy of tailored treatment for high-and low-risk medulloblastoma in adults: A large prospective phase II trial. Journal of Clinical Oncology. 2010;28:(Suppl 15):2003.

11. Beier D, Proescholdt M, Reinert C, et al. Multicenter pilot study of radiochemotherapy as first-line treatment for adults with medulloblastoma (NOA-07). Neuro-Oncol. 2018;20:400-410.

12. Packer RJ, Goldwein J, Nicholson HS, Vezina LG, et al. Treatment of children with medulloblastomas with reduced-dose craniospinal radiation therapy and adjuvant chemotherapy: A Children's Cancer Group Study. J Clin Oncol. 1999;17:2127-2136.

13. Kessinger A. High dose chemotherapy with autologous bone marrow rescue for high grade gliomas of the brain: a potential for improvement in therapeutic results. Neurosurgery. 1984;15:747-750.

14. Brandes AA, Bartolotti M, Marucci G, et al. New perspectives in the treatment of adult medulloblastoma in the era of molecular oncology. Crit Rev Oncol Hematol. 2015;94:348359.

15. Kool M, Korshunov A, Remke M, et al. Molecular subgroups of medulloblastoma: an international meta-analysis of transcriptome, genetic aberrations, and clinical data of WNT, SHH, Group 3, and Group 4 medulloblastomas. Acta Neuropathol. 2012;123:473-484.

16. Remke M, Hielscher $\mathrm{T}$, Northcott PA, et al. Adult medulloblastoma comprises three major molecular variants. J Clin Oncol. 2011;29:2717-2723. 